\title{
EFFECTS OF FLUIDS ON VIBRATION BALL MILL GRINDING
}

\author{
KAZUO SUZUKI AND YOSHITAKA KUWAHARA \\ Government Industrial Research Institute Nagoya, Nagoya 462
}

\begin{abstract}
Key Words: Grinding, Grinding Fluids, Viscosity, Dipole Moment, Surface Tension, Rittinger's Number
\end{abstract}
\begin{abstract}
Wet grinding of Si powder under seven environmental conditions was carried out, using a laboratory vibration ball mill. The physical properties of the grinding fluids used affected the increase of specific surface area. Based on the results of multiple regression analysis of the relation between Rittinger's number and the physical properties of grinding fluids, it was found that the grinding rate decreased with the increase of either viscosity or surface tension, and increased with dipole moment, in the range of the experimental conditions. These experimental results were studied from the viewpoint of fracture mechanics, considering the surface energy of materials and ball motion in the vibration ball mill with viscous fluids. It was also found that surface tension and dipole moment of grinding fluids affect the fracture energy of materials, and that viscosity affects the impact velocity (energy) of the ball.
\end{abstract}

\section{Introduction}

Grinding is an essential operation for improving the morphological characteristics of powder such as reduction of size, preparation of particle shape, increase of specific surface areas and deagglomeration. In ceramics processing, grinding is usually required because fine raw powder is necessary as the starting material. To develop industrial materials such as high-performance ceramics, the powder preparation technology (as well as shaping method and sintering technology) is very important. The microstructure of the sintered materials, which directly affect the properties of final products, depends greatly on the morphological properties of starting powder similarly to its chemical and crystallographical properties, ${ }^{12)}$ although the grinding process also causes a change in the chemical and crystallographical properties at the same time. ${ }^{14)}$

It is well known that wet grinding is a more effective means for comminution of fine particels than dry grinding. In wet grinding, the properties of grinding fluids affect the grinding mechanisms. The grinding fluids might affect the probability and relative proportion of impact, chipping and abrasion in comminution. On the other hand, grinding behavior is fundamentally claimed to be based on the fracture mechanics of individual particles, ${ }^{6,7)}$ and the mechanical strength of certain nonmetallic materials such as glass depends on the kind of environment and surface conditions. ${ }^{2)}$ In actual grinding, it is also important to determine the grinding conditions in a given system. The role of viscosity of the grinding

\footnotetext{
Received May 31, 1985 . Correspondence concerning this article should be addressed to K. Suzuki.
}

fluids in a laboratory ball mill was investigated for coarse particles both by Hocking et al. ${ }^{1)}$ and Kapur et $a l^{3)}$

The purpose of this paper is to examine how the properties of grinding fluids affect the increase of specific surface area of ground products in a laboratory vibration ball mill. The effects of both dipole moment and surface tension of the fluids on grinding rate were studies on the basis of fracture mechanics. The effect of viscosity was examined from the ball motion in the viscous fluids. Seven kinds of organic solvents, selected from the viewpoint of physical properties (viscosity, surface tension and dipole moment), were used in these experiments.

\section{Experimental Method and Materials}

The grinding experiments, in dry and seven environmental conditions, were carried out using a laboratory vibration ball mill for 200 hours. The amplitude and frequency of circular vibration were $1.5 \mathrm{~mm}$ and $1770 \mathrm{cpm}$, respectively. A mill (a pot: $600 \mathrm{ml}, 90 \mathrm{~mm}$ dia. $\times 95 \mathrm{~mm}$ depth) and grinding media (rods: $10 \mathrm{~mm}$ dia. $\times 10 \mathrm{~mm}$ length, density $3.1 \times$ $10^{-3} \mathrm{~g} / \mathrm{mm}^{3}, 830 \mathrm{~g}$ ), which were made of sintered silicon nitride, were used under the conditions indicated in Table 1. In this study, metal silicon powder (\#200, 99.9\% purity, Mitsuwa Chemical Co., Ltd.) was ground with $200 \mathrm{ml}$ of grinding fluids. As shown in Table 1, the mass of balls and materials in the mill were $830 \mathrm{~g}$ and $164 \mathrm{~g}$ corresponding to $J=0.7$ and $U=1.00$ respectively, where $J$ is defined as the ratio of volume of balls plus space between balls to volume of mill and $U$ is the ratio of volume of powder particles plus space between particles to volume of space between balls. ${ }^{83}$ 
Table 1. Experimental conditions

\begin{tabular}{|c|c|}
\hline Vibration ball mill & \\
\hline Amplitude of circular vibration & $1.5 \mathrm{~mm}$ \\
\hline Frequency of vibration & $1,770 \mathrm{cpm}$ \\
\hline Volume of mill body & $600 \mathrm{ml}$ \\
\hline Materials of mill body & $\mathrm{Si}_{3} \mathrm{~N}_{4}$ (sintered) \\
\hline \multicolumn{2}{|l|}{ Grinding media } \\
\hline Materials of media & $\mathrm{Si}_{3} \mathrm{~N}_{4}$ (sintered) \\
\hline Size of media & $10 \mathrm{~mm}$ dia $\times 10 \mathrm{~mm}$ len. \\
\hline Ball filling of mill & $J=0.70(830 \mathrm{~g})$ \\
\hline \multicolumn{2}{|l|}{ Powder } \\
\hline Materials & Si $(\# 200,99.95 \%)$ \\
\hline Density of materials & $2.32 \mathrm{~g} / \mathrm{cm}^{3}$ \\
\hline Powder fraction & $U=1.00(164 \mathrm{~g})$ \\
\hline
\end{tabular}

Seven organic solvents were used for grinding. The properties of these solvents ${ }^{10)}$ are listed in Table 2 with experimental results.

Particle size distributions of the ground products were measured by a photo extinction method based on sedimentation in the gravitational and centrifugal fields. The specific surface areas were obtained by the B.E.T. method, applying nitrogen or krypton gas adsorption at a temperature of $77.6 \mathrm{~K}$ after desorption at $383 \mathrm{~K}$ in vacuum.

\section{Results and Discussion}

Particles size distributions of products ground for 200 hours in seven organic solvents are shown in Fig. 1 with the result of dry grinding. These results clearly show that the distribution in dry grinding was very wide, and that wet grinding is more effective in obtaining fine powder than is dry grinding. In the case of dry grinding, a pot and balls were coated by the ground particles. The adhesive forces between particles and/or between surface of grinding media and particles cannot be disregarded, especially for fine powder in dry grinding. The impact force was reduced by the coated particle layer because of the cushioning effect. Especially for fine grinding, the difference in relative rate among impact, chipping and abrasion in grinding must also arise in both dry and wet grinding because of the suspension effect, namely, the dispersion effect.

On the other hand, it is not apparent from this figure whether the shape of the particles size distribution curves of the ground products depended upon the kind of grinding fluids. Graphs of specific surface area of ground products with grinding time are shown in Figs. 2(a) and (b) with the result of dry grinding. As shown in these figures, it is interesting that the grinding process did not reach the grinding limit in the time of 200 hours grinding under any environmen- tal condition. ${ }^{13)}$ The grinding limit ${ }^{15)}$ in wet condition may necessarily be reconsidered on the basis of fracture mechanics of individual particle.

All curves of specific surface area in Fig. 2 were linear throughout most of the grinding time. In other words, the increase of specific surface area was proportional to grinding time, and Rittinger's law $^{8)}$ is applicable to these results. In addition, it is interesting that the curve for hexane, the dipole moment of which is nearly equal to zero as shown in Table 2, was similar to that in dry grinding.

Rittinger's number and the physical properties of grinding fluids are listed in Table 2. The standard deviation of the density of the seven kinds of organic solvent used was so small that the effect of density was not considered here. In Table 3, the coefficient of correlation among three parameters (viscosity, dipole moment and surface tension) of grinding fluids and Rittinger's number are listed. It was not possible to recognize a correlation among such properties of grinding fluids, and the three parameters might be independent of each other. As shown in the same table, a negative correlation was observed between Rittinger's number and the viscosity or the surface tension. And a positive correlation was observed between Rittinger's number and the dipole moment. The values of the coefficients of correlation were low except that of correlation between Rittinger's number and the viscosity. The effect of viscosity, surface tension and dipole moment on the grinding rate cannot be directly shown by these coefficients of correlation, because all three parameters of grinding fluids affected Rittinger's number. Hence, the relation between Rittinger's number and each of the properties of grinding fluids was analyzed by a method of multiple regression analysis assumting the linear function of the three parameters of grinding fluids. The multiple correlation coefficient was 0.832 and the coefficient of determination was 0.692 . The effects of viscosity, dipole moment and surface tension of grinding fluids on Rittinger's number are illustrated in Figs. 3, 4 and 5, respectively. Here, these Rittinger's numbers were not the experimental data shown in Table 2, but were estimated from the results of multiple regression analysis using experimental data at fixed values (shown in figures) of other properties. The grinding rate decreased with increasing viscosity, increased with the dipole moment, and decreased with increasing surface tension in the range of this experimental condition.

It is known that the dipole moment and surface tension of liquids affect the fracture strength of materials because of the change of the surface energy. ${ }^{8)}$ The surface energy $U_{s}$ of the crack system, was described by Griffith for unit width of crack with the free surface energy $\gamma$ per unit area as 
Table 2. Physical properties of grinding fluids used and Rittinger's number

\begin{tabular}{llccccc}
\hline & \multicolumn{1}{c}{$\begin{array}{c}\text { Chemical } \\
\text { formula }\end{array}$} & $\begin{array}{c}\text { Density } \\
\left(\times 10^{-4} \mathrm{~g} / \mathrm{mm}^{3}\right)\end{array}$ & $\begin{array}{c}\text { Viscosity } \\
\left(\times 10^{-3} \mathrm{~Pa} \cdot \mathrm{s}\right)\end{array}$ & $\begin{array}{c}\text { Dipole } \\
\text { moment } \\
(\text { debye })\end{array}$ & $\begin{array}{c}\text { Surface } \\
\text { tension } \\
(\mathrm{dyn} / \mathrm{mm})\end{array}$ & $\begin{array}{c}\text { Rittinger's } \\
\text { number } \\
\left(\mathrm{m}^{2} / \mathrm{g} / \mathrm{h}\right)\end{array}$ \\
\hline Hexane & $\mathrm{CH}_{3}\left(\mathrm{CH}_{2}\right)_{4} \mathrm{CH}_{3}$ & 6.548 & 0.2985 & 0.085 & 1.791 & 0.118 \\
Toluene & $\mathrm{C}_{6} \mathrm{H}_{5} \mathrm{CH}_{3}$ & 8.623 & 0.5516 & 0.31 & 2.792 & 0.111 \\
Methanol & $\mathrm{CH}_{3} \mathrm{OH}$ & 7.866 & 0.5445 & 2.87 & 2.169 & 0.135 \\
Ethanol & $\mathrm{C}_{2} \mathrm{H}_{5} \mathrm{OH}$ & 7.850 & 1.078 & 1.66 & 2.148 & 0.129 \\
n-Propanol & $\mathrm{CH}_{3} \mathrm{CH}_{2} \mathrm{CH}_{2} \mathrm{OH}$ & 7.998 & 1.722 & 3.09 & 2.289 & 0.103 \\
Isobutyl alcohol & $\left(\mathrm{CH}_{3}\right)_{2} \mathrm{CHCH}_{2} \mathrm{OH}$ & 7.978 & 3.910 & 1.79 & 2.211 & 0.097 \\
Acetone & $\mathrm{CH}_{3} \mathrm{COCH}_{3}$ & 7.844 & 0.3040 & 2.69 & 2.201 & 0.145 \\
\hline Average & & 7.815 & 1.2012 & 1.783 & 2.229 & 0.120 \\
Std. dev. & & 0.622 & 1.2973 & 1.120 & 0.274 & 0.016 \\
\hline
\end{tabular}

At $20^{\circ} \mathrm{C}$.

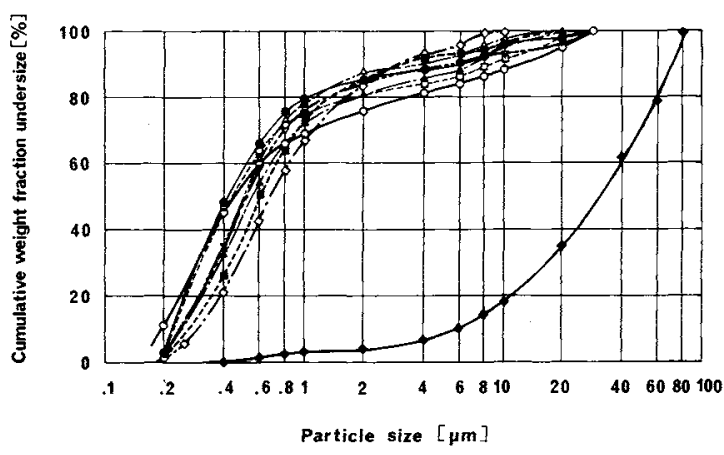

Fig. 1. Particle size distributions of Si powder ground for $200 \mathrm{hr}$ in eight environmental conditions with original powder. $O$, dry; $\boldsymbol{\Delta}$, hexane; $\nabla$, toluene; $\square$, methanol; ethanol; $\diamond, n$-propanol; $\mathbf{n}$, isobutyl alcohol; $\triangle$, acetone.

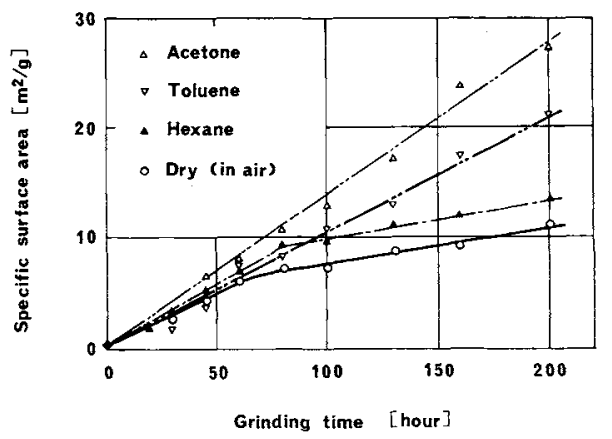

(a)

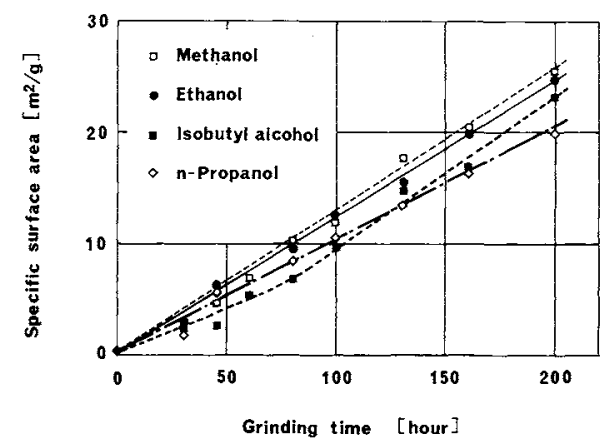

(b)

Fig. 2. Increase of specific surface of $\mathrm{Si}$ powder ground in eight environmental conditions.
Table 3. Correlation among properties of grinding fluids and Rittinger's number

\begin{tabular}{lrrrr}
\hline & Viscosity & $\begin{array}{c}\text { Dipole } \\
\text { moment }\end{array}$ & $\begin{array}{c}\text { Surface } \\
\text { tension }\end{array}$ & $\begin{array}{c}\text { Rittinger's } \\
\text { number }\end{array}$ \\
\hline Viscosity & 1.0000 & & & \\
Dipole moment & 0.1781 & 1.0000 & & \\
Surface tension & 0.0377 & -0.0410 & 1.0000 & \\
Rittinger's number & -0.7121 & 0.2534 & -0.2300 & 1.0000 \\
\hline
\end{tabular}

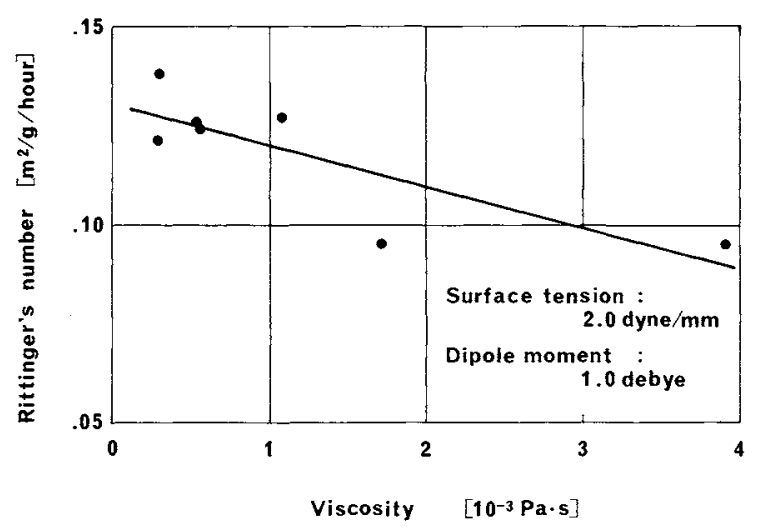

Fig. 3. Effect of viscosity of grinding fluids on Rittinger's number (values of Rittinger's number were corrected by multiple regression analysis).

$$
U_{s}=4 c \gamma
$$

where $c$ is the length of edge crack. For a static crack system, the total system energy becomes

$$
U_{t}=-\pi c^{2} \sigma^{2} / E+4 c \gamma
$$

where $\sigma$ and $E$ are the critical stress and Young's modulus of materials, respectively. An edge crack of length $c$ (limiting case of surface notch) may be considered to possess very nearly one-half the energy of an internal crack of length $2 c$. The Griffith equilibrium condition $d U_{t} / d c=0$ may now be applied, 


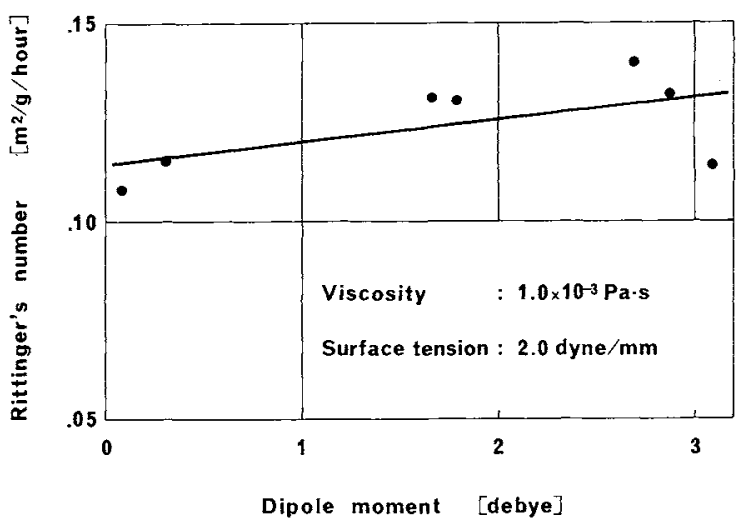

Fig. 4. Effect of dipole moment of grinding fluids on Rittinger's number (values of Rittinger's number were corrected by multiple regression analysis).

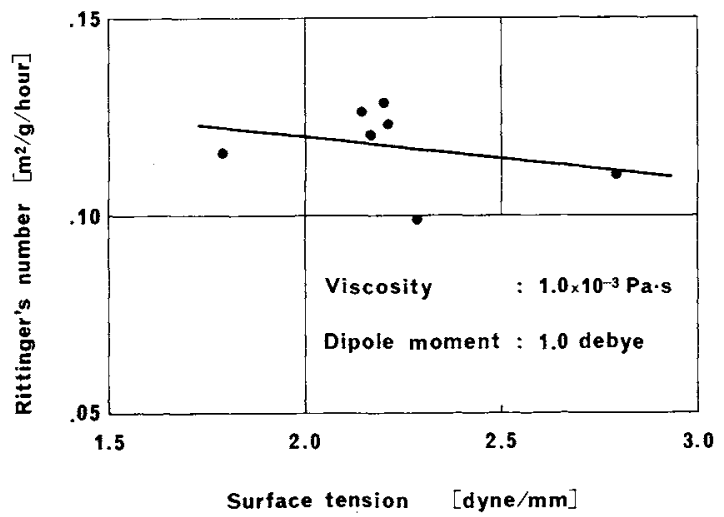

Fig. 5. Effect of surface tension of grinding fluids on Rittinger's number (values of Rittinger's number were corrected by multiple regression analysis).

giving the critical condition for fracture of materials as

$$
\sigma=(2 E \gamma / \pi c)^{1 / 2}
$$

for constant load and plane stress condition.

It is estimated that $c$ and $E$ are constants for same materials, and the critical stress for fracture is reduced with the decrease of surface energy of materials. The surface energy (interface energy) of a solid decreases with wetting by liquids, and the free energy changes at the interface as much as $W_{s}=\gamma_{s}-\gamma_{l}-\gamma_{i}{ }^{5)}$ Through contact with liquids, the interface energy of particles decreases as much as the value of surface energy (surface tension) of the liquids. And, at the interface between metal and liquids with permanent dipole moment, or between an ionized surface (if the surface of the silicon particle had been oxidized) and liquids, the interaction energy depends on dipole moment. ${ }^{11}$ ) Hence, the surface energy was likely to be reduced with the increase of the values of surface tension and dipole moment, and the grinding rate increased as a result. The dispersion effect is also important in grinding, and is also related to interface energy (dipole moment). The dispersion effect for fine particles was not expected in hexane, the dipole moment of which is nearly equal to zero.

The viscosity of grinding fluids was critically effective rather than the dipole moment or the surface tension, and may affect the behavior of suspended particles or the motion of balls. The effect of suspension (dispersion in liquids in the gravitational field) for coarse particles was discussed by Hockings et al. ${ }^{1)}$ and Kapur et al. ${ }^{3)}$ For fine particles, sedimentation in the gravitational field would not occur in the mill within a short time because of the low terminal settling velocity. The ball motion in the mill is important for fine comminution using the vibration ball mill. Vertical motion of a non-repulsive body and of a bed composed of repulsive bodies in a vibrating field have been analyzed by Kousaka et al., ${ }^{4)}$ but the effect of viscosity was not discussed in their paper. Ball motion is apparently affected by the viscosity of grinding liquids or the pulp.

In viscous fluids, the velocity of the ball decreases by the drag force $R_{f}$, as follows:

$$
R_{f}=-\frac{\rho A_{b} C}{2} u^{2}
$$

where $u$ and $A_{b}$ are the relative velocity and the projection area of the ball, $\rho$ is the density of grinding fluids and $C$ is the coefficient of drag. It is well known that the drag coefficient varies in different ranges of the Reynolds number. Reynonds' number is proportional to the velocity and diameter of the ball, and to the density of grinding fluids, and is inversely proportional to the viscosity of grinding fluids. The drag force becomes large with increasing viscosity if all the other parameters are fixed (the values of density of grinding fluids used are nearly equivalent), so that velocity of the ball would be further decreased. As previously stated, Rittinger's number decreased with increasing viscosity. The values of viscosity in Fig. 3 are those of organic solvent but Rittinger's number may depend on the viscosity of the pulp.

\section{Conclusions}

Based on the experimental results of vibration ball milling with seven griding fluids, the following conclusions were obtained.

(1) The grinding rate decreases with increasing viscosity of grinding fluids. It is suggested that the cause is a decrease in the impact velocity.

(2) The dipole moment of grinding fluids affects the grinding rate, although the effect was small under these experimental conditions.

(3) Although the effect of surface tension was also small, the grinding rate decreased with increasing surface tension of grinding fluids. 


\section{Acknowledgment}

This work was supported in part by a Grant-in-Aid from the Science and Technology Agency of Japan (the Special Coordination Fund for the Promotion of Science and Technology).

\section{Nomenclature}

\begin{tabular}{|c|c|c|c|}
\hline$A_{b}$ & $=$ & projection area & {$\left[\mathrm{m}^{2}\right]$} \\
\hline$C$ & $=$ & drag coefficient & {$[-]$} \\
\hline$E$ & $=$ & Young's modulus of materials & {$\left[\mathrm{N} / \mathrm{m}^{-1}\right]$} \\
\hline$J$ & $=$ & $\begin{array}{l}\text { ball filling of mill (ratio of volume of balls } \\
\text { plus space between balls to volume of mill) }\end{array}$ & {$[-]$} \\
\hline$R_{f}$ & $=$ & drag force & {$[\mathrm{N}]$} \\
\hline$U$ & $=$ & $\begin{array}{l}\text { powder fraction (ratio of volume of powder } \\
\text { particles plus space between particles to } \\
\text { volume of space between balls) }\end{array}$ & ler \\
\hline$U_{s}$ & $=$ & surface energy of crack system & {$[\mathrm{J}]$} \\
\hline$U_{t}$ & $=$ & total system energy & {$[\mathrm{J}]$} \\
\hline$W_{s}$ & $=$ & free energy of particles per unit area & {$\left[\mathrm{J} / \mathrm{m}^{2}\right]$} \\
\hline$c$ & $=$ & edge crack of length & {$[\mathrm{m}]$} \\
\hline$\gamma_{s}$ & $=$ & surface energy of particles per unit area & {$\left[\mathrm{J} / \mathrm{m}^{2}\right]$} \\
\hline$\gamma_{l}$ & $=$ & surface energy of liquid per unit area & {$\left[\mathrm{J} / \mathrm{m}^{2}\right]$} \\
\hline$\gamma_{i}$ & $=$ & interface energy per unit area & {$\left[\mathrm{J} / \mathrm{m}^{2}\right]$} \\
\hline$\mu$ & $=$ & viscosity of grinding fluids & [Ps s] \\
\hline$\rho$ & & density of grinding fluids & {$\left[\mathrm{kg} / \mathrm{m}^{3}\right]$} \\
\hline$\sigma$ & $=$ & critical stress of materials & {$\left[\mathrm{N} / \mathrm{m}^{2}\right]$} \\
\hline
\end{tabular}

\section{Literature Cited}

1) Hockings, W. A., M. E. Volin and A. L. Mular: Trans, Soc. Mining Eng., 220, 59 (1965).
2) Imanaka, O., S. Fujino and K. Shinohara: Bull. Japan Soc. Prec. Eng., 2, 22 (1966).

3) Kapur, P. C., A. L. Mular and D. W. Fuerstenau: Can. J. Chem. Eng., 43, 119 (1965).

4) Kousaka, Y., N. Maki and T. Yoshida: Kagaku Kōgaku, 37, $180(1973)$.

5) Kubo, K.: "Introduction to Mechano-chemistry," p. 30, Tokyo Kagaku Dojin, Tokyo (1978).

6) Kuwahara, Y., F. Saitoh and S. Yashima: J. Soc. Powder Tech. Japan, 19, 157 (1982).

7) Kuwahara, Y., F. Saitoh and S. Yashima: J. Soc. Powder Tech. Japan, 19, 211 (1982).

8) Lawn, B. R. and T. R. Wilshaw: "Fracture of Brittle Solid," Vol. 5, Cambridge University Press, Cambridge (1975).

9) Rose, H. E. and R. M. E. Sullivan: "Vibration Mills and Vibration Milling," Constable and Company, Ltd., London (1961).

10) Riddik, J. A. and W. B. Bunger: "Organic Solvents," Techniques of Chemistry 2, John Wiley \& Sons, Inc., New York (1970).

11) Sasaki, T. ed.: "Fundamentals of Interfacial Phenomenon," p. 217, Lecture on Surface Engineering 3, Asakura Shyoten (1973).

12) Schwier, G.: Proc. Int. Symp. Ceram. Comp. Engine, Hakone (Japan), (1983).

13) Suzuki, K. and Y. Kuwahara: KONA (Powder Sci. and Tech. Japan), 2, 2 (1984).

14) Suzuki, K., S. Tomura and Y. Kuwahara: J. Soc. Powder Tech. Japan, 20, 122 (1983).

15) Tanaka, T.: Kagaku Kōgaku, 18, 160 (1958). 